\title{
Digital Media, Young Adults, and Religion: An International Perspective
}

Moberg, Marcus and Sofia Sjö, eds. 2020. Digital Media, Young Adults, and Religion: An International Perspective. New York: Routledge. 192 pp. \$108.97. Hardcover. ISBN: 1138541613.

This volume is a collection of ten articles written by a panel of international contributors, who present and analyze the findings of the research project Young Adults and Religion in a Global Perspective: A Cross-Cultural, Comparative and Mixed-Method Study of Religious Subjectivities and Values in their Context (YARG). The Department of the Study of Religion at Äbo Akademi University in Turku, Finland, was responsible for this study. They gathered data from 13 countries-Canada, China, Finland, Ghana, India, Israel, Japan, Peru, Poland, Russia, Sweden, Turkey, and the United States of America-between 2015 and 2019. Participants were young adult university students ages 18 to 30. The book is written for scholars to contribute to current research on the theoretical and empirical levels in the growing field of religion, media, and digital culture, with emphasis on social media-approached here as a polymedia environment. The editors rightly suggest it will be of interest to those working in religious studies, digital media, communication studies, sociology, cultural studies, theology, and youth studies. I would suggest that scholars in mission studies (missiology) and psychology will also benefit from this work.

The book is divided into two parts. The first one offers three chapters that introduce the theoretical and methodological underpinnings of the study and frames the rest of the book. The first chapter gives a concise layout of the field of religion, media, and digital culture. It defines terms and summarizes the book's chapters. Then, the second chapter articulates the theoretical concerns of the book in terms of perspectives on agency and identity construction, connectedness and connectivity, and authority. The authors argue that identity in the digital age is increasingly constructed and performative, a product of the intersection of technology, social, affection, and emotional relational dimensions rooted in a specific context. On connectedness and connectivity, they approach it from the concept of participatory culture proposed by Henry Jenkins but with a welcoming nuance in which social media is recognized as holding the potential to both connect people and polarize them. When it comes to authority, the authors build on Weber's three sources of religious authority: scripture, tradition, and charisma, adding the fourth dimension of personal experience. With such a move, the book approaches the topic similarly to Heidi Campbell, who defends technology to be a religious-social shaping force. The third chapter introduces the methodologies, presents the findings, and discusses how the research contributes to nuance the notion of digital natives. The study combined three methods of data collection; 1) the general survey portrait value questionnaire (PVQ), 2) the faith q-sort (FQS), and 3) semi-structured thematic interviews. Readers interested in quantitative methods will be particularly attracted to observe FQS as a new instrument-how it is applied—and assess its potential usefulness.

The second part of the book offers seven chapters on applications and cases reporting the findings in seven specific countries_-Ghana, Peru, China, Israel, Turkey, Poland, and Finland. The YARG research project relied on the Inglehar-Welzel "Cultural Map of the World" (www.worldvalues- 
survey.org/WVSContents.jsp) to choose these seven particular contexts. Additionally, they selected countries that would achieve a wider religious variety.

The main strength of this work is its intercultural nature. The project was intentionally designed to move beyond Western contexts, providing an international perspective. Each chapter follows its own organization to present and analyze the data in a specific cultural context and the results are diverse. In Ghana, for example, participants reported that their online activities are complementary to offline ones. New media engagement allows them to follow their (offline) religious leaders, teachers, and religious groups, suggesting that digital media is intertwined with traditional religious authorities. In Peru, students use new media to find new resources as they take an active role in their religious learning. It appears Peruvian participants exercise a higher level of personal agency, acting more independently and self-directed than their Ghanaian peers. China has a very different profile as few respondents identify as religious or reported that religion is important. The authors conclude that the current intersection of media and religion remains largely unexplored in that country. The chapter on Israel might surprise the reader if she expects to find information on the Jewish religion. Instead, the authors take advantage of the multireligious landscape of the country to research among Arab Muslims and the Arab Druze people. They find that new media has a direct effect on Muslim participants as they engage in new media often and for a variety of religious purposes. However, the effect of new media on the religious lives of Druze participants is indirect due to the secretive nature of the Druze community, which lacks a digital footprint in content and activity. However, both religious groups reported being less religious than their parents. The chapters on Turkey, Poland, and Finland continue presenting how each context has its own peculiarities. In the end, readers will find a kaleidoscope of realities and diversity of findings that begins to paint an international picture of the intersection of new media, young people, and religion.

On a sidebar, the book's title is rightly less ambitious and more appropriate than the title of the YARG project. The latter proposes to generate a global perspective, while the book's title suggests an international one. This work represents a significant step toward a future global perspective, but readers should refrain from making generalizations.

I do not find major shortcomings but would like to offer two suggestions that would strengthen this volume. The editors state that the book provides "a truly macroscopic perspective on trends in religion amongst young adults” (i). Throughout the book, the trends are not clearly indicated and the findings presented are so diverse that the reader is left questioning if there are trends that can be compiled from the cases. It would have been fascinating to see a final chapter engaging with the findings, weaving possible trends, and integrating the many themes throughout the case chapters. With that said, the book does provide much-needed knowledge of particular contexts that other researchers may continue to build upon as well as a platform to ask new questions. Scholars interested in the particular seven countries will find great value, and other scholars will also benefit from their findings, methodologies, and possibilities of comparative studies.

The work also misses the opportunity to engage and integrate the concept of emerging adulthood from the field of developmental psychology. It is not that the authors were not aware of the theory, since it is mentioned in chapter three, but the theory and terminology are never developed or integrated. At times, the authors use young adults and emerging adults interchangeably, which readers may find imprecise. Emerging adulthood would assist this research because it recognizes the centrality of religion in this human life stage (18-30 years of age) and theorizes on how the college/university experience often triggers a more intense examination of one's religion and faith. 
Additionally, the theory is intercultural and would fit well with the international nature of this volume.

Scholars pursuing research that frames religion as a lived experience within complex webs of relationalities instead of the more traditional way of thinking in terms of orthodoxies and sets of beliefs and practices will appreciate the approach in this volume and the results it yields. This reviewer highly recommends purchasing the book as it contributes both to theoretical and empirical research. Also commendable is the deliberate invitation and encouragement to young scholars to join in this large-scale study and serve as contributors to this volume.

Paulo C. Oliveira

Independent Researcher

Pasadena, CA 